\title{
Cultural Basis of Sport Anglers' Response to Reduced Lake Trout Catch Limits
}

\author{
Richard W. Stoffle, Florence V. Jensen, and Danny L. Rasch \\ Survey Research Center, Institute for Social Research, University of Michigan \\ Post Office Box 1248, Ann Arbor, Michigan 48106, USA
}

\begin{abstract}
The cultural domain of southeastern Wisconsin anglers along Lake Michigan was assessed from responses to a state-proposed reduction in the daily allowable catch of lake trout Salvelinus namaycush. The study's baseline was an extensive random survey in 1980 of the area's anglers with respect to Lake Michigan fishery resources. The 1984 lake trout issue was addressed by a restudy involving a small dimensional subsample of 1980 respondents and was cross-validated with ethnographic interviews. The findings suggest that anglers have responded over time to the state's policy proposals in a manner consistent with a stable value system that is not seriously masked by changes in short-term attitudes about the fishery. The results further indicate that, once a good cultural data base is established, the sociocultural impacts of proposed fishery policies can be evaluated inexpensively by a restudy approach.
\end{abstract}

This paper presents research findings from a 1984 study that assessed the motivation of southeastern Wisconsin anglers who argued against a proposal by the Wisconsin Department of Natural Resources (WDNR) to reduce the daily catch of lake trout Salvelinus namaycush in the state's portion of Lake Michigan. A second goal of this analysis is to distinguish stable angler fishery values from changeable fishery attitudes. The analysis draws on and contributes to a growing literature on the anthropological analysis of fishing culture (Smith 1977; Acheson 1981; Maiolo and Orbach 1982; Pollnac 1982; Stoffle 1986). Finally, we explore the implications of sociocultural findings for the development of public policy (Caplan et al. 1975). Of special importance is the need to develop methods for conducting inexpensive policyrelevant studies. We conclude that Lake Michigan anglers do have a specific fishery cultural domain and that fishery policies can be based on knowledge of these fishery values.

The major sport fishes of Lake Michigan are yellow perch Perca flavescens, lake trout, rainbow trout Salmo gairdneri, brown trout Salmo trutta, coho salmon Oncorhynchus kisutch, and chinook salmon $O$. tshawytscha. Yellow perch and lake trout are the only native species in this group and the only ones to breed in the lake. The others ascend tributaries to breed, but suitable spawning habitats are limited and the lake populations of these species are sustained by hatchery production and stocking by natural resource agencies in the surrounding states. Lake trout, too, are heavily stocked; their once substantial population was decimated first by commercial overfishing and then by the parasitic sea lamprey Petromyzon marinus.

The fishery thus relies on state hatchery and stocking programs, and these are expensive to maintain. In early 1980 , faced with inflationary pressures and reduced federal support, the WDNR proposed to suspend hatchery production of coho salmon, citing its high cost relative to that of chinook salmon and a chronic problem with bacterial kidney disease in the coho salmon hatcheries. Other states faced similar budgetary problems, so there suddenly was a strong possibility that fishable stocks of coho salmon would disappear from Lake Michigan.

The proposed WDNR policy on coho salmon brought a vigorous reaction from sports anglers. They pointed out that coho salmon were an important part of their total season's catch. Indeed, WDNR's own Lake Michigan creel census counts for the previous 5 years showed that over half the fish caught from Sheboygan to Kenosha were this species. Charter boat captains said that coho salmon was their "bread-and-butter fish" because its season starts in May, 2 months before the chinook salmon season, thus lengthening the Lake Michigan fishing season. In addition, captains said that the coho salmon is the fish that "fills the box" on a typical charter or private fishing trip. "Filling the box" is a boater expression that means everyone on board caught their limit of fish and thus filled the large ice chest or "box" that boats carry to keep fish fresh. The more abstract meaning of the expression implies a successful fishing trip.

A few months before the WDNR announcement, in September 1979, the Reborn Lake Project was established at the University of Wiscon- 
sin-Parkside. The project's goal was a holistic assessment of the economic, nutritional, health, and quality-of-life impacts that salmon and trout stocking in Lake Michigan had on the inhabitants of southeastern Wisconsin. The principal vehicle for this assessment was a lengthy questionnaire that would be administered to anglers throughout 1980. The WDNR staff recognized the potential value of this survey and proposed adding two multiple-part survey questions that would yield angler evaluations of policy alternatives actually under consideration by the agency, as well as reactions to a proposed salmon-trout stamp as an alternative to higher license fees to support the agency program. The results of the survey were published (Stoffle et al. 1983) and will be summarized later in this paper. In short, anglers were strongly opposed to elimination of coho salmon stocking and, partially because of this, the WDNR granted a 2-year reprieve to the program. Furthermore, to the department's surprise, solid support emerged for a salmon-trout stamp. With the help of an angler coalition, the Wisconsin legislature passed a stamp bill that took effect in 1982, in time to support continuation of the coho salmon stocking. Thus, the WDNR and the public interacted constructively to resolve an important policy issue.

A new policy debate arose in 1983. Angler catches of lake trout had risen sharply-for example, WDNR statistics show that the harvest by Racine anglers increased from 1,200 fish in 1980 to 9,750 fish in 1982-and the department was concerned about overfishing the stock. Conversely, the WDNR proposed a decrease in the daily catch limit per angler. The angler response was familiar but confusing to the WDNR because anglers now maintained that the lake trout was their "bread-and-butter fish," the species that "fills the box" on a typical trip. So, a mere $3 \frac{1}{2}$ years after the debate over the coho stocking, anglers were defending the lake trout in terms once reserved for the coho salmon.

What could account for this change? Had the lake trout been reevaluated by the anglers? Had the fishery itself changed, making salmon harder to catch? Had anglers simply targeted a species that was easier to catch? Had the 1980 survey provided changeable angler attitudes instead of stable angler values regarding fishing, thus being of short-term rather than of long-term utility of WDNR managers? Could such research findings be inexpensively "double checked" to see if they were still accurate? In 1984, we undertook to an- swer these questions by resurveying a small subsample of the 1980 respondents - a "restudy."

Surveys can elicit at least two types of research findings: those based on attitudes and those based on values. Were the findings only useful for evaluating one policy proposal and then subject to rapid change, they would be termed attitude-based. New attitude data would have to be generated each time a new policy was proposed. Opinion polls are a common form of attitudinal data collection.

Surveys can also elicit statements that measure values. Value-based evaluations of one policy should be useful for predicting the evaluations of future policies. Anthropologists have found that many values persist throughout the lifetime of the individual and even over generations.

It is difficult to tell whether or not a survey has elicited value-based or attitude-based evaluations. A restudy, however, is one means of determining the type of data elicited by a survey. Survey findings can also be evaluated through ethnographic interviews and participant observation.

\section{Methods}

Restudy dimensional sample. - Dimensional sampling was chosen as the most appropriate method of selecting interviewees for the 1984 restudy. According to Arnold (1970) dimensional sampling can be used when there is an explicitly delineated universe, when the most important dimensions of this universe are known and can be used to develop a typology, and when this typology serves as a sampling frame for selecting a small number of cases from the universe.

The universe of southeastern Wisconsin Lake Michigan anglers had been defined by survey and ethnographic techniques. The 1980 survey used a stratified random sampling methodology. Assumptions regarding types of anglers and fishing patterns derived from 4 months of ethnographic research. The sample was stratified by (1) city: Kenosha, Racine; (2) type of fishing: pier-shore, boat; (3) time of day: early morning, noon, evening; and (4) day of the week. The survey findings were representative of the estimated 17,708 anglers who fished along the southeastern Wisconsin portion of Lake Michigan during the 1980 Reborn Lake Project interviews.

Analysis of the 1980 survey responses and indepth oral history interviews of anglers in the spring of 1981 suggested that, from a fishery management perspective, there were important new angler distinctions. Four types of anglers are now 
considered to be distinguishable: pier-shore anglers, small boaters, heavily capitalized boaters, and charter boaters. Other angler characteristics, such as time or day of fishing, proved not to be significant. City where fishing was done proved to have some policy implications.

The three new typology distinctions are all in the boater category. The "small boaters" perceive themselves as having special needs as anglers and, in Racine, have an informal organization with a spokesperson who is recognized by the city administration. They commonly launch their boats at public access points where no fee is charged. Their boats are usually much smaller than those used by other types of boaters and so these anglers are more concerned with protection from severe storms that frequently come off Lake Michigan. The "heavily capitalized boaters" go far into the lake and have tens of thousands of dollars invested in their boats and fishing equipment. Many have thousands of dollars invested just in fishing lures. "Charter boaters" were an all but invisible class in 1980, even though there were dozens of them in both cities. By 1984, they had organized a statewide association to help represent their special concerns.

The dimensional sample was drawn from this redefined typology. The restudy dimensional typology contained the variables of "city where fished" and "type of angler." The typology thus provided a two (Racine, Kenosha) by four (piershore angler, small boater, heavily capitalized boater, charter boater) analytical frame. Two anglers were selected from each cell, even though Arnold (1970) suggested that one case per cell is sufficient. Each angler was locally recognized as knowledgeable about this type of fishing in his city. All 16 of the chosen anglers agreed to be interviewed.

Even though dimensional sampling is an accepted research method, there are still questions as to when it is most appropriately used. Romney et al. (1986) suggested a model for predicting the minimal number of informants needed to describe a cultural domain. They found three critical factors: the cultural competence of the informants, the required confidence level, and the proportion of questions to be classified correctly. Based on these criteria, a sample of four highly competent $(90 \%)$ informants could provide correct answers $85 \%$ of the time at a $99 \%$ confidence level. The findings of Romney et al. argue for the validity of our restudy dimensional sample because it contains 16 highly competent individuals and only 10 questions to be answered about the cultural domain of sportfishing.

Restudy instrument and interview. - The restudy instrument concentrated on the two 1980 WDNR policy alternative questions. Each interviewee was asked to respond to the questions just as the questions had been asked in 1980 . Interviewees were asked if they had changed their feelings about these policies since 1980 . Interviewees were asked if they would speak for other anglers like themselves regarding these policy alternatives and whether or not others had changed their feelings about these policy alternatives. Finally, interviewees were asked what they and other anglers like them felt about the WDNR proposed daily catch limit on lake trout.

Most interviews were tape-recorded. Although the core of the interview involved just the 10 questions, interviewees were encouraged to frame the issues in their own words and to introduce new issues. As a result, interviews lasted on the average $1 \frac{1 / 2}{h}$, the briefest being $20 \mathrm{~min}$ and the longest $3 \mathrm{~h}$.

Ethnographic verification.-Findings from the dimensional sample interviews were cross-checked with the 16 interviewees as well as with persons recognized as knowledgeable about both the Lake Michigan fishery and the activities of anglers. Knowledgeable persons included professional WNDR fishery managers as well as local experts. Each received a draft of the paper, time for written responses, and a follow-up interview. Interviewees were reinterviewed if they desired, otherwise written comments were received. Some follow-up interviews lasted more than $3 \mathrm{~h}$.

Public presentations of the research findings at the monthly meeting of the major local sportfishing clubs provided a further cross-check of dimensional sample findings. After the hour-long presentation, anglers freely discussed the findings among themselves and with the researchers. Drafts of the research paper were made available before and after these club meetings.

\section{Analysis of Restudy Findings}

\section{WDNR Policies}

Stocking alternatives. - In the 1980 survey, anglers were asked to evaluate on a five-point scale the extent to which they felt positively or negatively towards four WDNR stocking alternatives (Table 1). The only policy alternative to receive an overall positive response was to maintain or increase the current stocking levels through use of 
TABLE 1.-Comparison of 1980 and 1984 angler responses to Wisconsin Department of Natural Resources policy alternatives for Lake Michigan.

\begin{tabular}{|c|c|c|c|}
\hline \multirow{2}{*}{\multicolumn{2}{|c|}{ Stocking alternatives (ranked) }} & \multicolumn{2}{|c|}{ Evaluation score } \\
\hline & & $\begin{array}{c}\mathrm{I} 980 \\
(N=213)\end{array}$ & $\begin{array}{c}1984 \\
(N=16)\end{array}$ \\
\hline (1) & $\begin{array}{l}\text { To maintain or increase current } \\
\text { stocking levels through a Lake } \\
\text { Michigan salmon-trout stamp }\end{array}$ & 10.2 & 100.0 \\
\hline (2) & $\begin{array}{l}\text { To maintain coho salmon stock- } \\
\text { ing at present level and reduce } \\
\text { brown and rainbow trout stock- } \\
\text { ing }\end{array}$ & -33.4 & -31.2 \\
\hline (3) & $\begin{array}{l}\text { To eliminate coho salmon stock- } \\
\text { ing and increase that of chinook } \\
\text { salmon }\end{array}$ & -54.9 & -81.3 \\
\hline (4) & $\begin{array}{l}\text { To generally reduce stocking and } \\
\text { keep present cost of fishing li- } \\
\text { cense }\end{array}$ & -69.9 & -100.0 \\
\hline
\end{tabular}

${ }^{a}$ Responses were recorded on a five-point scale from positive to negative. The evaluation score was produced by combining positive and negative responses.

a Lake Michigan salmon-trout stamp. The 1980 response would have been more positive but anglers were not certain salmon-trout stamp monies could be earmarked for stocking. The 1984 anglers were even more positive about the stamp than the 1980 anglers (Table 1). This came after they had purchased the stamp for the previous 3 years and had observed that stamp revenues were being spent on the fishery. Sport fishermen of all four types were willing to pay to help support the Lake Michigan fishery.

All of the remaining policy alternatives were given an overall negative response by both the 1980 and 1984 anglers. The least unpopular of these was to maintain coho salmon but to reduce that of brown and rainbow trout. However, anglers did not want to increase the stocking levels of a valued species like chinook salmon by reducing the stocking levels of another valued species, coho salmon. The 1984 anglers were totally against any reduction in stocking simply to keep the cost of fishing licenses stable. This response is consistent with their expressed willingness to support the fishery with a salmon-trout stamp.

After the restudy anglers responded to the 1980 WDNR policy alternatives, they were asked whether or not they had changed their views of these stocking issues over the past couple of years. All but one of the 16 respondents (94\%) said they still held the same views. All interviewees said that other anglers also held the similar views. These responses are consistent with those of the recog-
TABLE 2. - Comparison of 1980 and 1984 angler preferences for the allocation of management resources to Lake Michigan fish species by the Wisconsin Department of Natural Resources.

\begin{tabular}{lcc}
\hline & \multicolumn{2}{c}{ Preference rank } \\
\cline { 2 - 3 } Species & $1980(N=213)$ & $1984(N=16)$ \\
\hline Rainbow trout & 2 & 3 \\
Chinook salmon & 3 & 4 \\
Lake trout & 4 & 5 \\
Yellow perch & 5 & 2 \\
Brown trout & 6 & 6 \\
Coho salmon & 1 & 1 \\
\hline
\end{tabular}

nized local experts and comments made at the fishing club meetings. The data suggest that anglers have remained consistent in their evaluation of the four 1980 WDNR fishery management policy alternatives, and that value-based rather than attitude-based understandings were measured by this question in the 1980 survey.

Resources for fish species. - The second 1980 question requested that anglers rank six fish species according to the amount of WNDR fish management resources that should be invested in each. In 1980, anglers wanted the WDNR to invest most resources in rainbow trout, chinook salmon, and lake trout (Table 2). Even though anglers considered coho salmon to be their "bread-and-butter fish" in 1980, stocks of this species were perceived to be in sufficient supply. In 1984, anglers were asking that most WDNR resources be invested in coho salmon, yellow perch, and rainbow trout. This change in angler priorities corresponded with a rapid shift from coho salmon to lake trout as the primary target fish. Lake trout ranked fifth in 1984. For both periods, then, anglers preferred that the WDNR allocate fish management resources for fish species that were in need of extra assistance rather than primary target species.

Summary. - The survey and ethnographic data suggest that sports anglers have remained consistent in their evaluations of Lake Michigan fish and fishery management alternatives. These evaluations revolve around the value of fish for food and sport. Coho salmon and rainbow and brown trout are great fighters and are highly valued for sport. Chinook salmon are reasonable fighters and big enough to be trophies. Yellow perch are the best to eat of the six species, and they are strong traditional favorites among anglers. Lake trout are poor fighters ("it's like pulling a boot full of water up from the bottom," said one angler) and they have an oily taste. These data suggest that anglers prefer 
to have a diversity of fish species in Lake Michigan and do not simply emphasize management of primary target species.

\section{The 1984 Lake Trout Proposal}

If Lake Michigan anglers have remained consistent in their evaluations of fishery management practices, how do anglers explain the 1984 concern for the lake trout as their "bread-and-butter fish?" The 16 restudy anglers were asked what they, and others like them, felt would be the effect if the WDNR limited the daily catch of lake trout to one fish per person. Twelve of the anglers (75\%) were against the policy, three were neutral, and only one was positive about the policy. All of the anglers felt that other anglers of their type shared their views.

Only some of the pier-shore anglers, who rarely catch the lake trout, perceived themselves to be unaffected by the WDNR proposal. All boat anglers, especially heavily capitalized ones, and charter boaters, perceived that the WDNR policy would be a disaster for them. Naturally, it is these types of anglers who were most vocal against the WDNR proposal. It is they who were saying the lake trout is "our bread-and-butter fish."

Did such comments, made to help protect catch levels of lake trout, conflict with similar statements made about coho salmon in 1980? Discussions with the restudy anglers suggested an explanation for what they felt was a consistent way of evaluating the fishery.

Why the shift to lake trout? - The two main theories as to why sport fishermen shifted to lake trout as a primary target species are that lake trout are easier to catch than other species, and that a shortage of coho salmon forced the shift. Many WDNR fishery managers and some anglers have argued that the availability of coho salmon has not changed over this period but, instead, the coho salmon became harder to catch. This argument suggests that anglers targeted the lake trout because they were easier to catch. The further implication is that sport fishermen will always shift to the easiest to catch and most available fish species.

Many anglers and some WDNR managers, however, believe that the shift to lake trout occurred because of a drastic decline in the number of Lake Michigan coho salmon, not because lake trout are easy to catch, and that anglers were forced to target lake trout in order to have fish to catch during the early part of the season. Proponents of this theory argued that the shift to lake trout in- volved major economic and recreational costs for the anglers because most boats had to be outfitted with metal lines, heavier reels, and new baits; new fishing techniques had to be learned; lake trout are perceived to be low-quality food fish; and lake trout are not fighting fish, so, catching them reduces sporting enjoyment.

Ethnographic interviews and survey data from the 1984 restudy strongly supported the "forced to shift" theory. The following quote by a charter boat captain best summarizes the typical angler comment in the in-depth interviews:

\begin{abstract}
It is no secret that chinook, coho and lake trout are the three top fish in this area. Out of over 2,400 fish I caught in this area only 20 of them were rainbows and less than that were browns. We wouldn't have caught half of that many if we could have been fishing coho in the spring. I'm not gonna take people out and not catch them anything. So there-we're out looking for lake trout and we found them. But it's tougher fishing lake trout than fishing salmon. You're fishing lake trout primarily on the bottom and in quite deep water anywhere from 60 to 110 feet and it's just a lot more work. We would much rather fish salmon. You know, we thank God that we do have lake trout to take over when the salmon aren't here.
\end{abstract}

These observations are consistent with the 1984 resource allocation scores (Table 2): coho salmon went from a rank of sixth in 1980 to first in 1984 . These data document that anglers prioritize WDNR fish management resources on the basis of which fish species they perceive most needs WDNR help rather than in terms of which are the primary target species. Were anglers motivated by ease-of-catch values, they would emphasize more management resources be invested in the primary target species. As was the case for stocking alternatives, the allocation data suggest that anglers value a diversified fishery; in 1984, they perceived coho salmon to be most in need of WDNR resources. The data support the hypothesis that anglers were forced to primarily target the lake trout because of a real or perceived shortage of Lake Michigan coho salmon.

Filling the box, the prime motivation?-When explaining why they were "forced to shift" to lake trout, sport anglers said they lost the coho salmon and needed a fish to "fill the box" during the 2 months of the summer fishing season. It is a common term among anglers, but it requires ethnographic interpretation as a value-based explanation for angler behavior. Boaters indicate the success of the fishing trip by saying "we filled the 
box"; that is, everyone got their limit. Similarly, pier-shore anglers publicly indicate their success by holding up a string of fish. These public expressions of success raise a series of related questions about the the primary reason that Lake Michigan anglers fish. Do anglers only fish in order to fill the box? How many fish are required to make a trip successful? Will anglers retarget to any type of fish in order to fill the box? What other variables are used by anglers to evaluate the fishing experience? The few data available provide some preliminary answers.

In-depth ethnographic in terviews suggested that anglers are motivated to fish because they highly value sport, food, and social recreation. The type and size of fish caught reflect the degree of the sporting experience and the quality of food expected. Large catches of fish are used by anglers to fill the home freezer and so provide a steady annual diet of fish for the family. Once the needs of immediate and extended families are met, the fish become a central ingredient in a complex system of barter which is often characterized as "the subterranean economy." The number and type of fish caught seem to be key variables in the evaluation of the fishing experience. These elements constitute parallel and interactive continuums. Not catching fish or only catching fish of low perceived quality, such as common carp Cyprinus carpio, would constitute a bad trip. It would be hard to rationalize $\$ 20,000$ of boat and equipment only in terms of social recreation. Success begins when catching exciting sport fish is combined with sufficient numbers of fish caught, so that all participants can have something to take home. One 15$\mathrm{kg}$ chinook salmon would physically fill the box, but, by itself, would mean that only one person had caught a fish and that the trip had been a failure. Anglers do not have to reach the legal catch limit in order for the trip to be a success, but being able to fill the box generally indicates that success was achieved.

Sport, food, and social recreation provide the basic rationalizations for the enormous financial and emotional expenditures of sports anglers. The relative contribution of each of these elements to anglers' evaluation of fishing success has not been fully studied. It is certain, however, that filling the box is important as a public indication of success but not the total evaluation of the fishing experience.

Within this system of evaluation, it does not make sense to shift to lake trout simply because they are more accessible than coho salmon. Up to some point, smaller catches of hard-fighting, goodtasting coho salmon clearly offset full catch limits of lake trout. At issue here is the point at which increased fishing effort, combined with diminished coho salmon catches, caused most sport fishermen to shift to lake trout. Our data suggest it took a drastic reduction in coho salmon catch levels before the shift occurred. It was a problem that greatly exceeded in scope and complexity the problem of just not filling the box.

\section{Conclusion}

This research suggests that fishery policy deliberations for Lake Michigan should consider the culture of fishing; that is, the domain of primary and interrelated sport anglers values. A minimal list of values should include those dealing with the nutritional, economic, sport, and social aspects of Lake Michigan fishing. Like any cultural domain, these values can be scientifically studied and, once fully documented, can become the basis of longterm and critical understandings about the relationship between the culture of fishing and effective fishery management policy.

Policymakers who manage a fishery require two types of information: the key environmental, biological, and sociocultural variables that affect the fishery, and the condition of each of these at the time of a policy decision. While the key environmental and biological variables are well known and documented through longitudinal research, there are few studies that document the sociocultural variables and there are no longitudinal sociocultural studies for the Great Lakes. This research suggests the utility of establishing a general sociocultural data base and conducting policy-specific restudies as required. It can be expensive to develop a general sociocultural data base, but it is required in order to identify and understand the interrelationships of key fishery values. Once the general data base is in place, cost-effective restudies can rapidly update selected data relevant to fishery management decisions. The sociocultural variables that affect fishery policy can be monitored as well as the environmental and biological ones. If managers support the development of general sociocultural data bases and learn how to monitor them, human inputs can become important scientific factors in fishery policy.

\section{References}

Acheson, J. M. 1981. Anthropology of fishing. Annual Review of Anthropology 10:275-316.

Arnold, D. 1970. Dimensional sampling: an approach 
for studying a small number of cases. American Sociologist 5:147-150.

Caplan, N., A. Morrison, and R. Stambaugh. 1975. The use of social science knowledge in policy decisions at the national level: a report to respondents. University of Michigan, Institute for Social Research, Ann Arbor.

Maiolo, J., and M. Orbach, editors. 1982. Modernization and marine fisheries policy. Ann Arbor Science Publishers, Ann Arbor, Michigan.

Pollnac, R. B. 1982. Sociocultural aspects of technological and institutional change among small-scale fishermen. Pages 225-247 in J. Maiolo and M. Orbach, editors. Modernization and marine fisheries policy. Ann Arbor Science Publishers, Ann Arbor, Michigan.
Romney, A., S. Weller, and W. Batchelder. 1986. Culture as consensus. American Anthropologist 88:313 338.

Smith, M. E. 1977. Those who live from the sea: a study in marine anthropology. West, St. Paul, Minnesota.

Stoffle, R. 1986. Caribbean fishermen farmers: a social assessment of Smithsonian king crab mariculture. University of Michigan, Institute for Social Research, Ann Arbor.

Stoffle, R., D. Rasch, and J. Jensen. 1983. Urban sports anglers and Lake Michigan fishery policies. Coastal Zone Management Journal 10:407-427. 